\title{
Curie Point Depth, Heat Flow and Geothermal Gradient Determined from Analysis of Aeromagnetic Data over parts of the Lower Benue Trough and Anambra Basin, Nigeria
}

\author{
*ANYADIEGWU, FC; AIGBOGUN, CO \\ Department of Physics, Michael Okpara University of Agriculture, Umudike, Abia State \\ *Corresponding Author Email: fzinoz@gmail.com
}

\begin{abstract}
This paper evaluates the aeromagnetic data over parts of the Lower Benue Trough and Anambra Basin of North central and Southeastern Nigeria obtained from the Nigerian geological Survey Agency, Abuja to quantitatively determine the Curie Point Depth, Geothermal gradient, and Heat flow using Oasis montaj software, Fourpot software, and Surfer software. The results revealed that the average Curie point Depth of the Study area is $8.07594 \mathrm{~km}$, the Geothermal gradient obtained has an average value of $73^{\circ} \mathrm{C} / \mathrm{km}$, areas with low and intermediate geothermal gradient are, Southeast of Obubra, Northeast of Obi, North West of Odolu, and Awgu. The study area has an average heat flow of $170 \mathrm{~mW} / \mathrm{m}^{2}$, it is observed from the map that the areas around Igunmale, Abakaliki, Udi, Ejekwe and some area around Nkanu East have high heat flow rate attributed to presence of intrusive rock. Consequently, the study area is characterized by low, intermediate and high magnetic anomalies, the most prominent trend observed is in the ENE -WSW and NE-SW minor trend direction and has high heat reservoir potential which can be harnessed as geothermal energy, there is also a possibility of high temperature and pressure hydrocarbon reservoir potential.
\end{abstract}

\section{DOI:https://dx.doi.org/10.4314/jasem.v25i10.10}

Copyright: Copyright $\odot 2021$ Anyadiegwu and Aigbogun. This is an open access article distributed under the Creative Commons Attribution License (CCL), which permits unrestricted use, distribution, and reproduction in any medium, provided the original work is properly cited.

Dates: Received: 22 August 2021; Revised: 17 September 2021; Accepted: 06 October 2021

Keywords: curie point Depth, Spectral analysis, geothermal gradient, Heat flow

The role energy plays can never be exaggerated, and there is barely any activity that is free of energy. Over the years, human population and industrial activities has kepth increasing and as such depleting non renewable energy sources to meet up its energy requirement. Finding alternate energy sources such as geothermal energy can be achieved by carrying out research employing geophysical surveys aimed at delineating potential energy resources to mitigate the irregularities in energy generation. A geophysical survey simply measures the physical properties of the earth in other to precisely define its composition, structure and probably origin. Understanding the Earth's composition and structure will in turn provide us the necessary knowledge on which physical property to harness. Several geophysical methods exist, each particular method is sensitive to a particular physical property, example are magnetic susceptibility, density elastic moduli, dielectric constant, electrical conductivity, and so on. This can be directly or indirectly applied in our search for energy alternatives by employing either of the geophysical methods or combining them. The magnetic method measures the spatial variations in the strength of the geomagnetic field, which is applicable in metalliferous mineral deposit exploration, investigation of engineering and construction sites, and Archaeological investigations. The gravity method measures the spatial variations in the strength of the gravitational field of the earth, and is applicable in fossil fuel and bulk mineral deposit exploration, underground water exploration, engineering and construction sites investigation. Both methods are integrated and used as reconnaissance tools in oil and gas exploration (Patterson and Reeves, 1985). Potential field methods such as gravity and magnetics gives the room to determine the thickness of sediments and temperature gradient, the two most important inputs in the determination of heat flow critical for predicting hydrocarbon generation in potential hydrocarbon reservoirs and geothermal resources. In any area, the Earth's magnetic field is affected by geological structures, composition and magnetic minerals present, and is attributed to disparity in the amount of magnetite present in the rocks. Subsurface materials vary from place to place and therefore alter the patterns of the Earth's magnetic field from place to place. The magnetic map allows visual inspection of the faults, folds, and upper crust in Earth structure (El Sayed, 2016). Magnetic maps are crucial tools in 
geophysical exploration for subsurface mapping. A study of the shapes, trend and intensities on a magnetic map can reveal much information about the subsurface features. This information includes the location, size, shape, volume, magnetic susceptibility, strike, plunge, Dip and depth of the features (Witter et al., 2016). The age of a feature and type of material suggested in some cases may be estimated by logging (Biswas, 2017). Geothermal resources supply vital information on the sustainable power source represented by the Earth's internal heat (Elbarbary et al., 2018). Curie depth isotherm together with heat flow assessment would significantly compliment the geophysical information of the area and bridge the gap of lacking crustal temperature information. The assessment of variations of the Curie isotherm of an area provides valuable information about the regional temperature distribution at depth and the concentration of subsurface geothermal energy (Tselentis, 1991). Measurements have shown that a region with significant geothermal energy is characterized by an anomalous high temperature gradient and heat flow, therefore expected that geothermally active areas would be associated with shallow Curie point depth (Nuri et al., 2005). Hence, the objective of this paper is to evaluate the total magnetic intensity map for estimation of the Curie point depth, heat flow, and geothermal gradient within the study area.

\section{MATERIALS AND METHODS}

Study area: The study area covers part of Southeastern Nigeria and parts of the North central or middle belt, it lies between latitude $6^{\circ} 00^{\prime} \mathrm{N}$ to $7^{\circ} 00^{\prime} \mathrm{N}$ and longitude $7^{\circ} 00^{\prime} \mathrm{E}$ to $8^{\circ} 30^{\prime} \mathrm{E}$. it covers a total surface area of about 18,150 square kilometers, and is within the Lower Benue Trough and Anambra Basin. The study area is comprised of 10 formations (Figure 1.3), the oldest of these formations belong to the Albian age Asu River Group deposited in the first sedimentary cycle which comprises mostly of Shales with localized sand stones, silt stones, and limestone (Olade, 1975), and is found in the Abakaliki-Afikpo Basin and Mfamosing in the Calabar Flank. The youngest of these formations is the Bende-Ameki formation which includes the Nanka sands of the Upper to Middle Eocene age. The stratigraphic succession of these formations with the age of deposition is depicted in Figure 1. Nanka formation is overlain by Ogwashi-Asaba formation which comprises mostly of sandstones, shale's, and lignite beds. These are the tertiary units and constitute the pro-Niger delta Eocene to recent sequence (Fatoye and Gideon, 2013). Data Acquisition: The airborne magnetic data was acquired from the Nigerian Geological Survey Agency which was obtained from recent airborne survey by Furgo Airborne. The Airborne magnetic data was acquired with a $3 \mathrm{x}$
Scintrex CS2 Cesium Vapour magnetometer flown on an aircraft at $500 \mathrm{~m}$ flight line spacing in Universal Transverse Mercator (UTM) projection system. The flight parameters of the aeromagnetic data are: Flight line spacing $(500 \mathrm{~m})$, Tie line spacing $(2 \mathrm{~km})$, Terrain clearance $(80 \mathrm{~m})$, Flight direction was NW-SE while the Tie line direction was NE-SW. A total number of six (6) 1:100,000 sheet Total magnetic intensity (TMI) data sheet was acquired as secondary data from the Nigerian geological survey agency Namely Sheet 287 (Nsukka), Sheet 288 (Igunmale), Sheet 289 (Ejekwe), Sheet 301 (Udi), Sheet 302, and Sheet 303 (Abakaliki). The six (6) Tmi sheets were obtained in Geosoft file format and were merged to produce the Total magnetic intensity of the whole study area depicted in figure 2 .

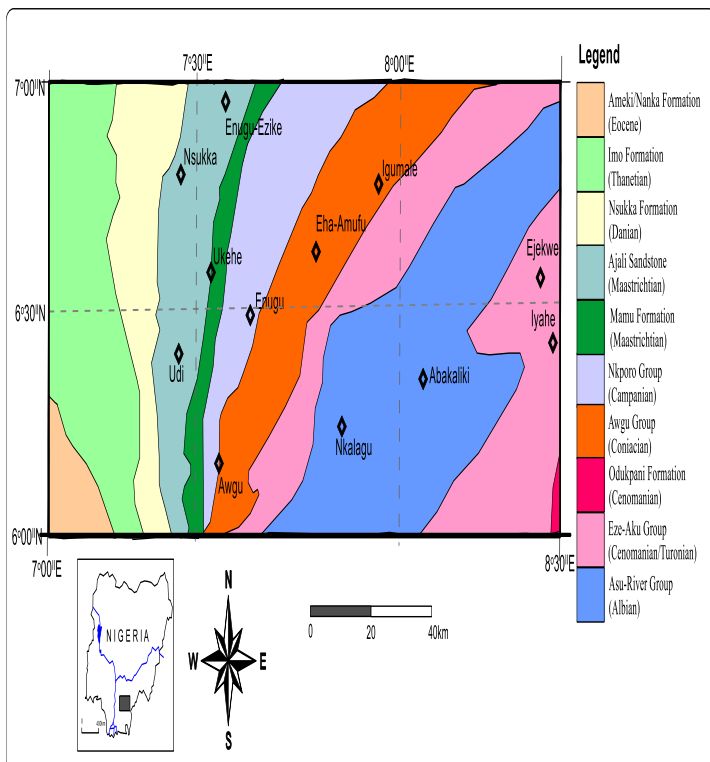

Fig 1: Geology map of the study area. (Redrawn after Offodile, 1976). 


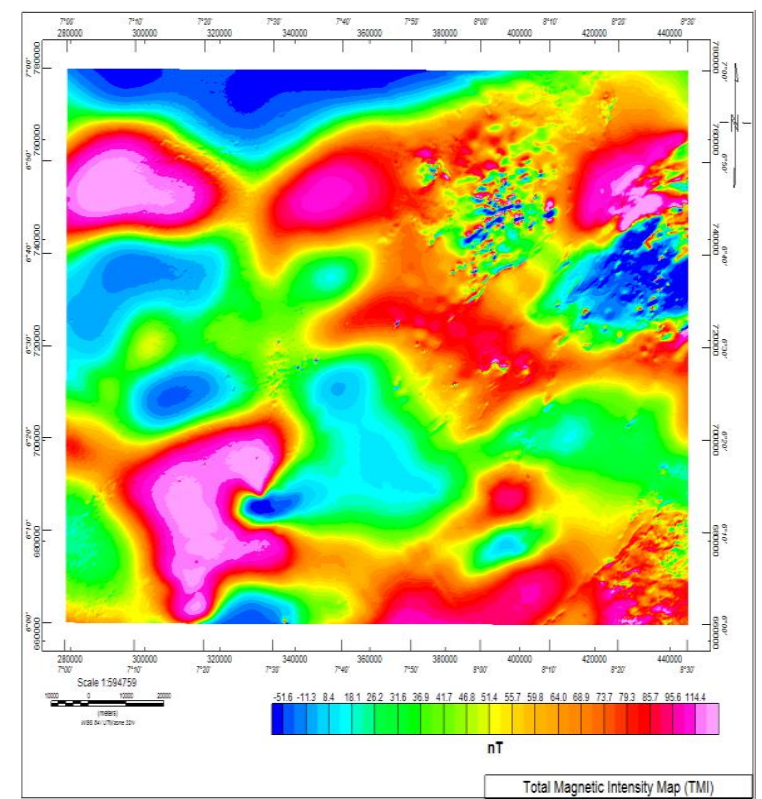

Fig 2: The Merged Total magnetic intensity (TMI) map of the study area, comprising of the 6 sheets.

The original TMI grid (figure 2) was processed, filtered and transformed to other grids using Geosoft Oasis Montaj software with associated extensions of the package such as MAGMAP (to generate Reduction to equator map, First Vertical Derivative, Second Vertical Derivative, Analytical signal) and SPI (to generate the Source Parameter Image Map).

The ESRI ArcGIS software by ESRI was used to relate and overlay various layers of information, such as geology, magnetic data, and the structures, and were extracted from the vertical derivatives using the ArcGis.

Fourpot software was used to produce the average spectral energy plot which was performed on the 40 windowed overlapping magnetic data, the data which was windowed from the Geosoft Oasis Montaj software.

The Golden software surfer software was used to produce the 3-dimensional depth to basement map from the spectral analysis' results.

Rockworks software was used to generate the Rose diagram for the structural trend analysis of the area.

Reduction to Equator (RTE), Regional-Residual Separation, Upward Continuation, Horizontal Gradient Method and Vertical derivatives are the qualitative analysis techniques performed on the magnetic data to enhance features of interest.

The Filtered merged magnetic data over the study area was divided into 40 spectral blocks (Labelled 1-40) with an area of 40sq km, (Fig. 3) and was subjected to processing to generate as many depth points as possible for a better depth estimation and perfect representation.

Digital signal processing software (four pot version 1.3) program employing the fast Fourier transform technique was used to transform the residual magnetic data into the radial energy spectrum for each block. The average radial power spectrum was calculated and displayed in a semi-log figure of amplitude versus frequency.

Data Analysis: Curie-point depth is the depth at which crustal rocks reach their curie temperature, or, it is the depth at which the rocks reaches the temperature of $580{ }^{\circ} \mathrm{C}$, it is considered as the index of the bottom of a magnetic source, due to ferromagnetic minerals converting to paramagnetic minerals. The curie depth was estimated using the statistics spectral analysis methods based on the work of Spector and grants (1970), Bhattacharyya and Leu (1975), Okubo et al., (1985).

$$
d=2\left(Z_{z}\right)-Z_{o}
$$

$\mathrm{d}$ is the curie depth point, $\mathrm{Z}_{\mathrm{z}}$ is the depth to deep magnetic source, $Z_{o}$ is the depth to the shallow magnetic source.

Recall equation: $\mathrm{Z}=-\mathrm{m} / 4 \pi ; \mathrm{m}$ is the slope, $\mathrm{Z}$ is the depth to the magnetic source, and the equation represents the frequency unit which is in circle perkilometre, for deep magnetic source,

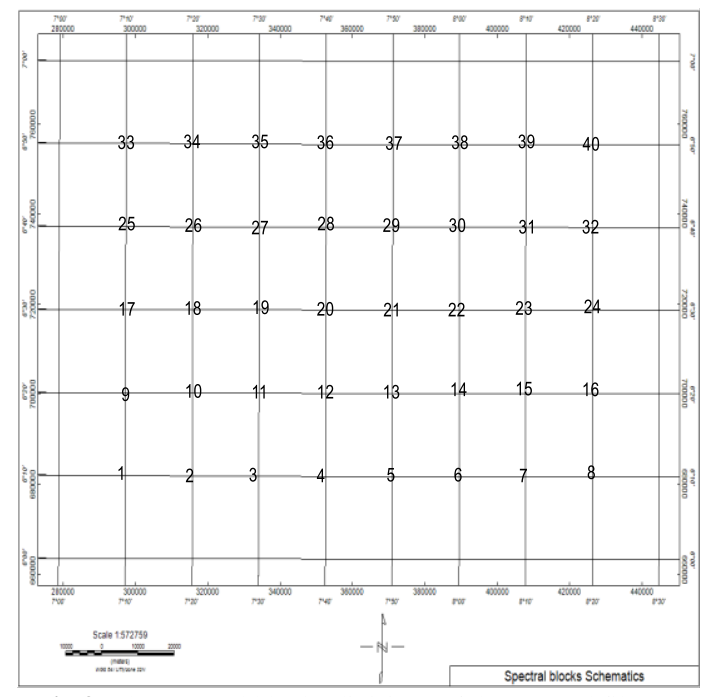

Fig 3: The spectral blocks divisions of the merged filtered magnetic data of the area

$$
Z_{z}=-m_{z} / 4 \pi
$$


for shallow magnetic source,

$$
Z_{o}=-m_{o} / 4 \pi
$$

Substituting equation 19 and 18 into equation 17

$$
\begin{array}{r}
d=2\left(-m_{o} / 4 \pi\right)-\left(-m_{o} / 4 \pi\right) \\
d=1 / 2 \pi\left[\left(m_{o} / 2\right)-m_{z}\right] \ldots \ldots \ldots \ldots \ldots
\end{array}
$$

The geothermal gradient is a calculation of the variation of temperature with increasing depth, it is an indication of the heat emanating from the earth's core up to the surface, the average temperature increases at the rate of $25^{\circ} \mathrm{C}$ for each kilometer depth (Wolfson, 2012), the geothermal energy is driven by this variation in temperature, considering the earth to be one dimensional, the geothermal gradient and the heat flow are therefore related by the Fourier's law by thus:

$$
q=\lambda(d T / d z)
$$

$\mathrm{q}$ is the heat flow, $\chi$ is thermal conductivity, $d T / d z$ represents the geothermal gradients Abraham et al., (2015).

The Curie temperature $\vartheta_{c}$ can also be defined as:

$$
\vartheta_{c}=(d T / d z) d
$$

$\mathrm{d}$ is the curie-point depth obtained from the spectral magnetic analysis.

As long as there is no external heat source impact on the surface of the earth and the curie-point depth, the earth's surface temperature is $0^{\circ} \mathrm{C}$ and $d T / d z$ is therefore constant (Kasidi and Nur, 2012b). The Curie temperature depends on magnetic mineralogy Curie temperature of magnetite $\left(\mathrm{Fe}_{3} \mathrm{O}_{4}\right)$, for example, is at approximately $580^{\circ} \mathrm{C}$, an increase of titanium (Ti) contents of titanomagnetite $\left(\mathrm{Fe}_{2}-\mathrm{xTi}_{\mathrm{x}} \mathrm{O}_{3}\right)$ causes a reduction of the Curie temperature. A Curie-point temperature of $580^{\circ} \mathrm{C}$ and thermal conductivity of 2.5 $\mathrm{Wm}^{-1}{ }^{\circ} \mathrm{C}^{-1}$. In addition to equation 6 , the heat flow is defined between the curie depth (d) and the heat flow (q) as follow

$$
q=\lambda\left[\frac{\theta}{d}\right]
$$

\section{RESULTS AND DISCUSSION}

The Total magnetic intensity map comprising of merged sheets is displayed in figure 4, the map shows raw magnetic intensity values of the distinctive rock within the area, magnetic intensity values ranging from low $-51.6 \mathrm{nT}$ to high $114.4 \mathrm{nT}$, a great part of the study area are characterised by high magnetic intensity which its peak are indicated by pink or orchid color with intensity beyond $95.5 \mathrm{nT}$ (Uzo-Uwani, Oju, IsiUzo, Oji-River, Awgu, Nkanu West, and sparsely within Oha-Ozara, Ikwo, and Obubra) and the low intensity areas are depicted in blue coloration which is largest northwest of the TMI map. The study area is characterised widely of intermediate magnetic intensity range between 26.2 and 55.7 nT with green and yellow colour. This is distributed majorly all over the map and is dominant when compared with the magnetic highs and lows. The total magnetic map of the area was reduced to the magnetic equator this is as a result of the data being acquired close to the equator which the study area falls within, this reduction to the magnetic equator performed on the Total magnetic intensity map shows little variation in the observed magnetic signature when compared to the TMI map. However, the implication of the magnetic data being reduced to the magnetic equator is the inverse relationship between the observed intensity value and the magnetic susceptibility of the individual rock, an effective way to counter this is to subject the reduced to magnetic equator data to its inverse so as to equate the relationship between the magnetic intensity and the magnetic susceptibility, a method which is not really necessary in most case.

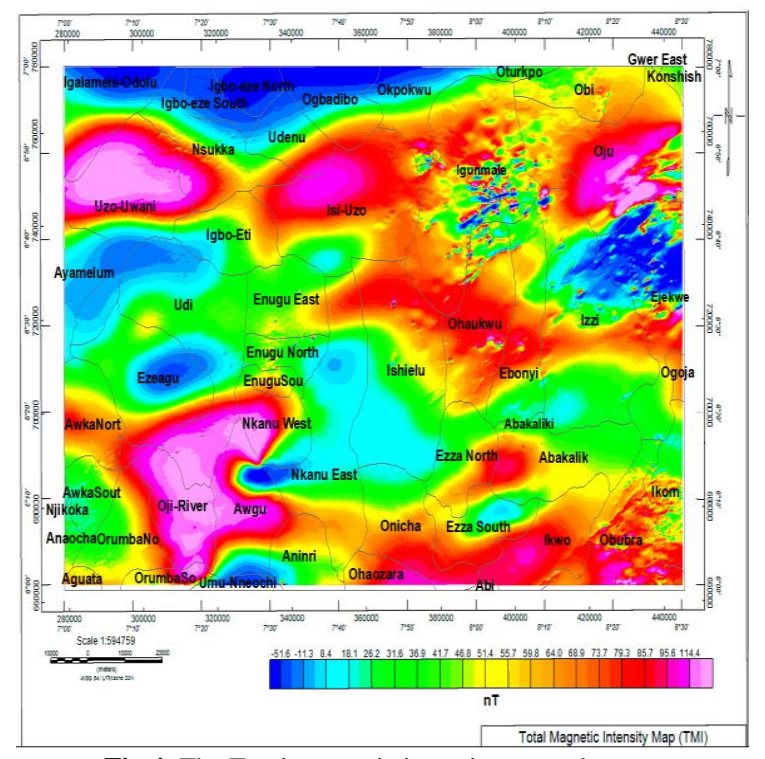

Fig 4: The Total magnetic intensity anomaly map.

The reduced TMI map yielded the Reduction to magnetic equator map depicted as figure 5, the magnetic intensity value ranges from $-41.9 \mathrm{nT}$ to 102.1 nT, the RTE magnetic anomaly map shows both low, intermediate and high frequency anomalies which represents the low, intermediate and high magnetic signature within the area, the areas with high observed magnetic intensity are the areas with low magnetic susceptibilities, and the areas with the low magnetic 
intensity are those with the high magnetic susceptibility which can be confirmed when magnetic or gravity data is modelled to generate magnetic Susceptibility.

The RTE map also shows the variation of both the regional and the residual anomaly by the varying wavelength observed, long wavelengths anomalies represent the regional magnetic anomaly mostly, while short wavelength anomalies represent residual magnetic anomaly sources which are due to localised mineralization. The RTE map indicates that the area under study is largely comprised of thick sedimentary cover as the most prominent wavelength are those of the long wavelength observed in the western and the southern part of the map, other areas with shorth magnetic wavelength are those around Igunmale, Ejekwe and some part of Obubra which falls in the eastern and the south-eastern part of the map respectively.

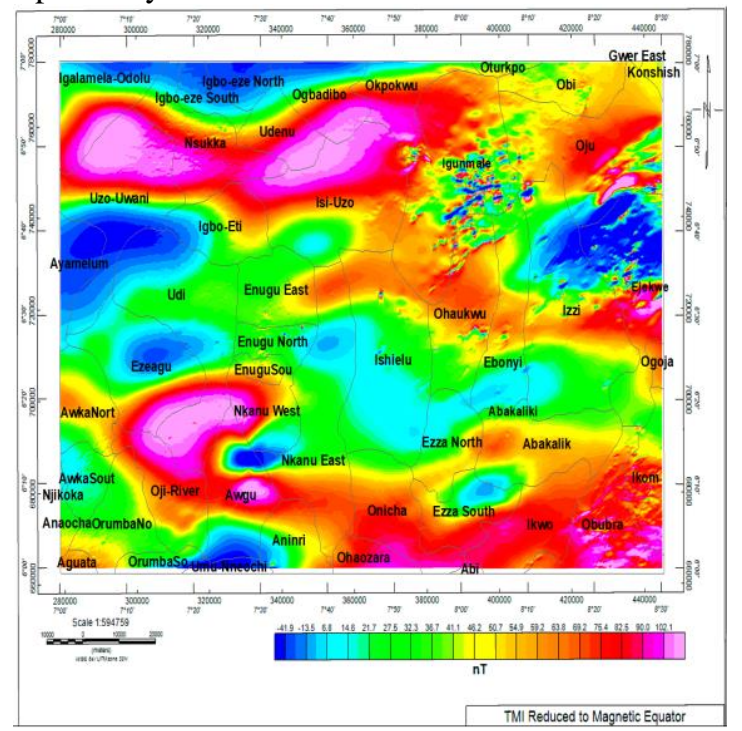

Fig 5: The TMI reduced to the magnetic equator.

The residual anomaly map shows the spatial distribution of magnetic anomaly, the residual filter enhances the residual/ localised/ remanent magnetic anomaly within the area, it does this by simply separating magnetic effects due to the Earth's core from the magnetic effect due to the crust, it minimizes the regional magnetic effect from the raw data, and this account for the presence of short wavelength anomaly within the area as seen in the figure 6 a displayed as the Residual anomaly map. This shows the area with high magnetic susceptibility in low observed intensity (Blue) and the areas with low magnetic susceptibility in high magnetic intensity (pink), the residual magnetic intensity values range from $-19 \mathrm{nT}$ to 18.6nT, the areas with prominent positive observed magnetic intensity values (pink coloration) are due to the presence of sedimentary rock such as shale, sandstone, and limestone. Most short wavelength magnetic anomalies are within the eastern and the southwestern part of the map (Ejekwe, Igunmale, Ikom, Obuora), in general, anomalies in the study area exhibit the characteristics of both low and high short wavelength magnetic signatures from the rocks, these are due to the near surface basement activity within the sediments, these kind of anomaly are characteristic of mineralized zone within the sediments, magmatism are usually accompanied by mineralization especially Metalliferous minerals of the order of Lead and zinc sulphides associated with copper (Chalcopyrite), they occur in loads and veins, wavelength variation along a profile line $\mathrm{A}$ to $\mathrm{B}$ on the map (Figure $6 \mathrm{~b}$ ). The regional anomaly map emphasises the regional trend of the area, they are magnetic anomaly due to the effect of regional magnetic response of rocks, they are mostly comprised of long wavelength Anomaly as seen in profile A-B (figure $7 \mathrm{~b}$ ) running from west to east on the regional anomaly map and the regional map trends in the NE-SW direction as seen in figure 7a.

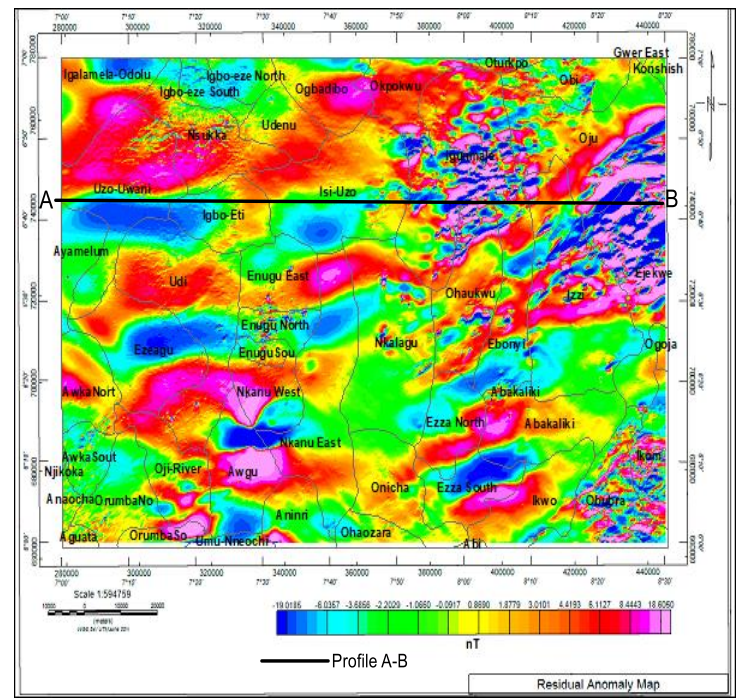

Fig 6a: The residual magnetic anomaly map generated over the area, with a profile line A to B

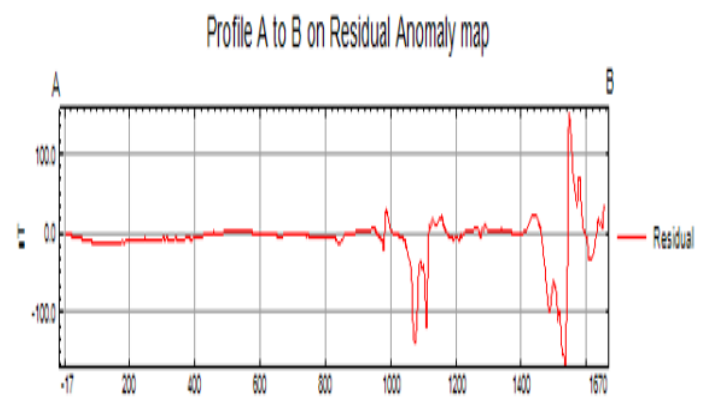

Fig 6b: The residual anomaly variation along profile $\mathrm{A}$ to $\mathrm{B}$ on the residual anomaly map 


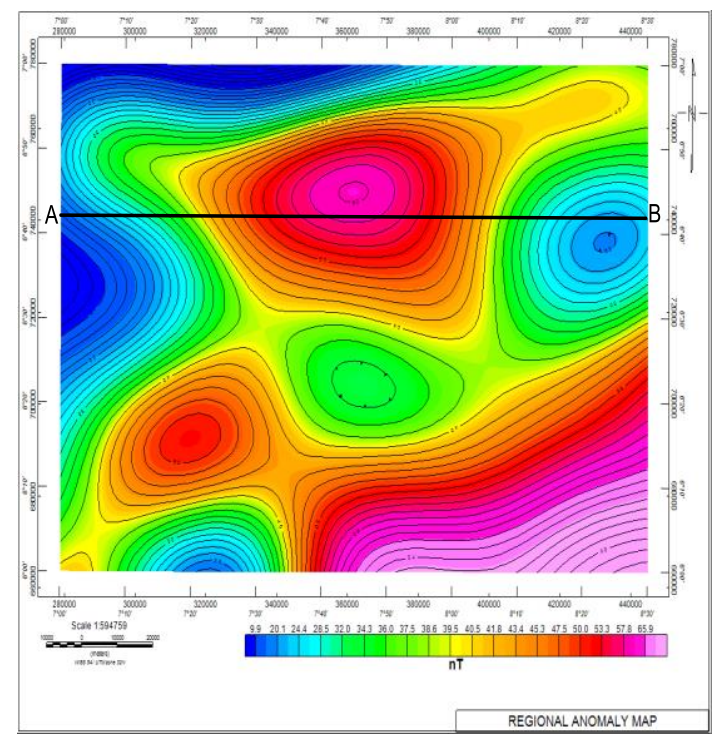

Fig 7a: The regional anomaly map of the area with a profile line A to $\mathrm{B}$ running across.

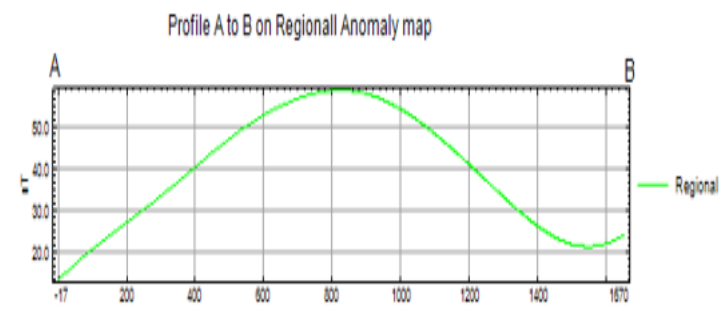

Fig $7 \mathrm{~b}$ : The regional magnetic anomaly variation across a profile A to $\mathrm{B}$, showing the Wavelength nature of the regional anomaly.

Vertical derivatives were used to observe near surface magnetic features associated with some geological structures, these near surface magnetic features were highlighted and extracted to produce a composite structural map of the area, these structures were defined by linear narrow magnetic low caused by weathering along a fault plane which oxidizes magnetic minerals to non-magnetic minerals (joints can have a similar magnetic expression), and linear magnetic high which may be discontinuous in nature due to magnetic minerals precipitated in the fault plane. The first vertical derivatives emphasise the shallower anomaly and are calculated in either space or frequency domains, the $1^{\text {st }}, 2^{\text {nd }}$ and $3^{\text {rd }}$ vertical derivatives were computed so as to examine the variation of the localised magnetic signature with decreasing depth as seen in figure 8,9 and 10 , the Horizontal derivatives method was also computed to map the edges of magnetic sources as seen in figure 11. The vertical derivative maps enhances high frequency anomalies (short wavelength) which are anomalies due to shallow magnetic bodies while the horizontal derivatives simply sharpens boundaries between anomalies and thus gives a clearer difference in the shapes of the body causing the anomalies. In figure 11, the lineaments indicate faults, folds or geomorphic lineaments such as fracture zones, shear zones, and igneous intrusion, these are all indications of a mineralized zone. The various structures extracted from the various map combination of the first to third vertical and the Horizontal gradient methods were highlighted and displayed in figure $12 \mathrm{a}$ as the structural map of the area, the trend analysis of those structures were produced and the orientation determined by the rose diagram (figure 12b), the most prominent trend observed is in the ENE -WSW and NE - SW minor trend direction. The present of magnetic structures were largely present in areas around Ikom and Obubra, Ejekwe north, Igunmale, Nsuskka, Enugu North and some other part of the map, the presence of these structure are indication of the remanent/localised magnetisation or short wavelength magnetic signature (high frequency) resulting from near surface lithological intrusions, these signature are the same with those observed in the residual anomaly map but are only more pronounced with more structural emphasis.

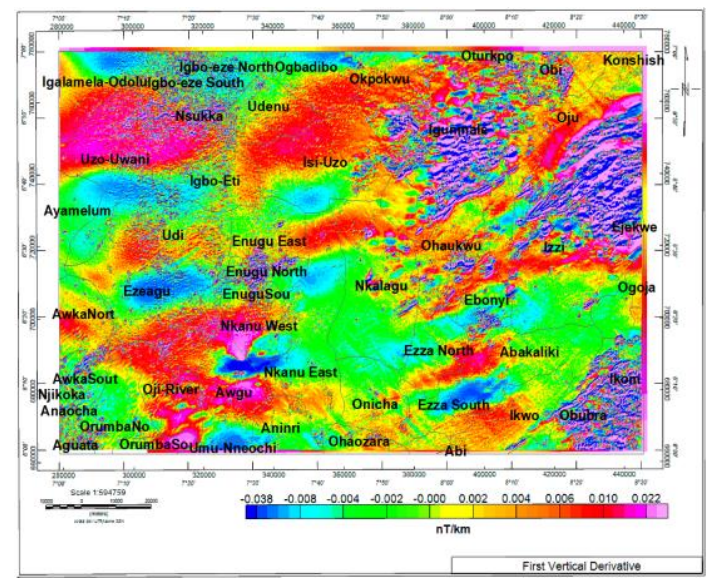

Fig 8: The First vertical derivative (1VD) of the TMI map of the area

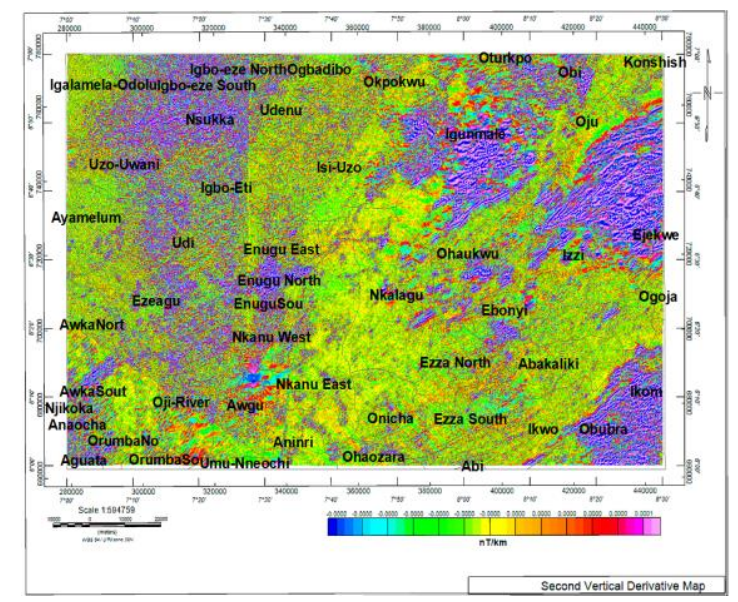

Fig 9: The Second vertical derivative map (2VD) of the TMI map of the area 


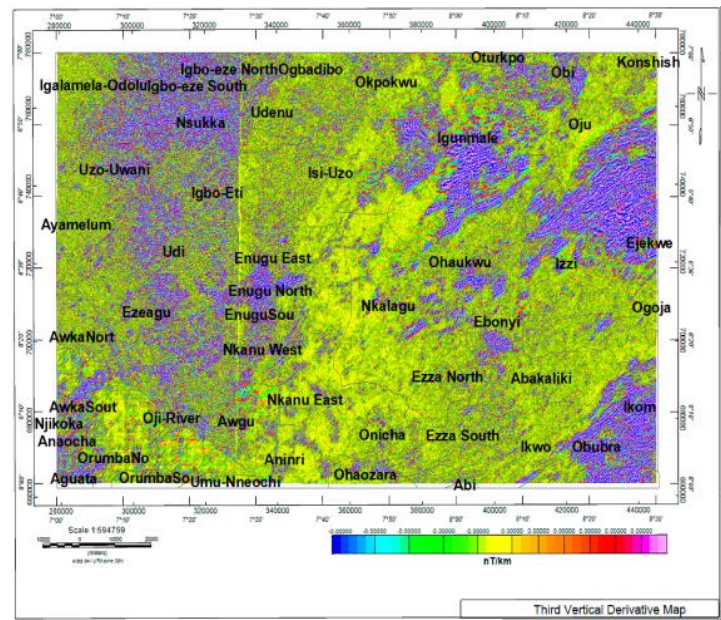

Fig 10: The Third vertical derivative Map (3VD) of the TMI map

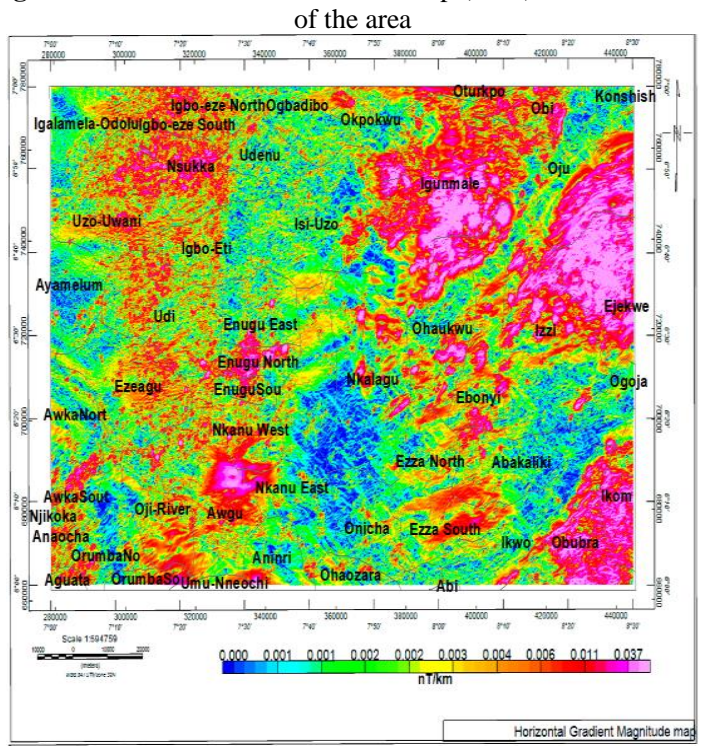

Fig 11: The Total Horizontal Derivative/Gradient map of the study area.

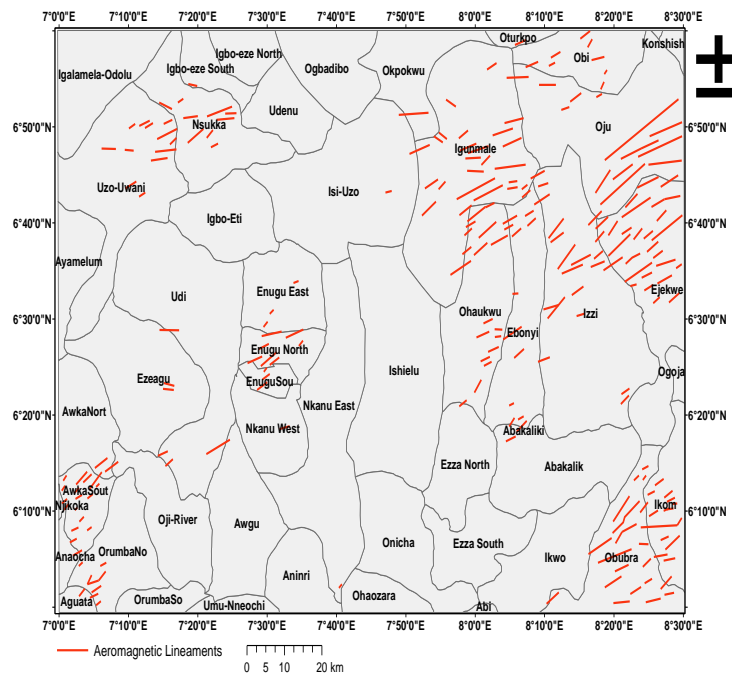

Fig 12a: The structural map of the area

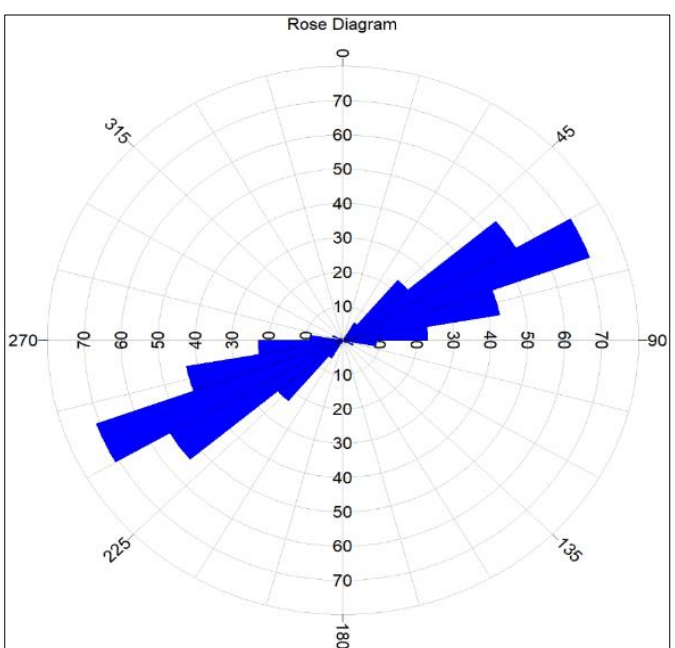

Fig 12b: The rose diagram for trend analysis over the area

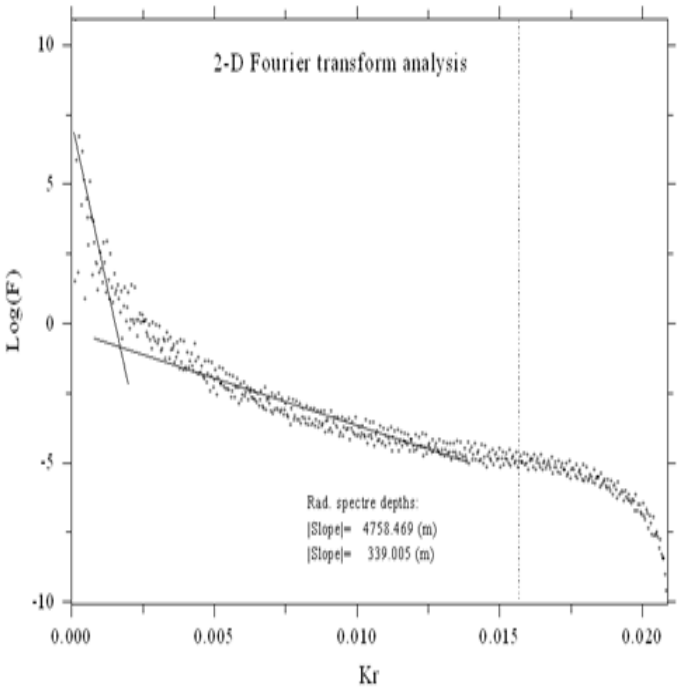

Fig 13: The average radial power spectrum was calculated and displayed in a semi-log figure of amplitude versus frequency for block 2.

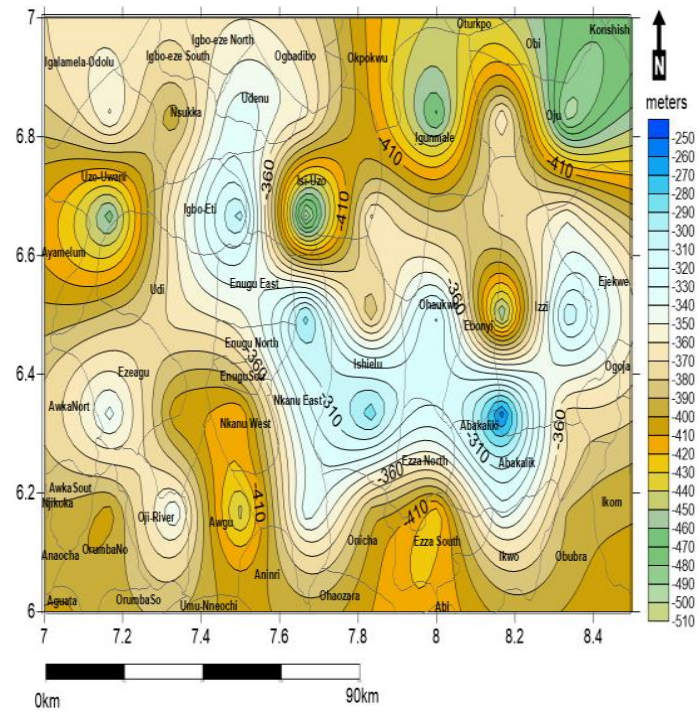

Fig 14a: 2D Shallow depth magnetic depth $\left(D_{2}\right)$ 


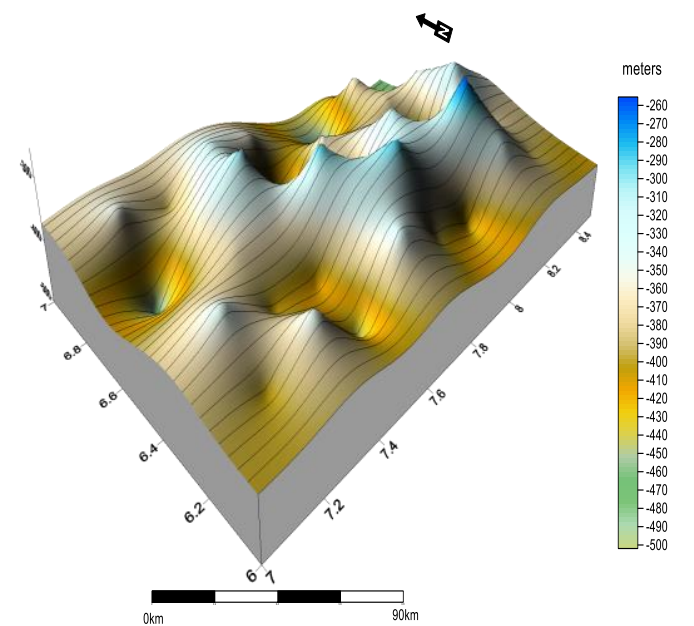

Fig 14b: 3D Map of the Depth to Shallow magnetic source $\left(D_{2}\right)$

Two depth values were determined by the spectral depth technique depicted in blocks 1-40 (fig. 13), they include the depth to shallow $\left(\mathrm{D}_{2}\right)$ magnetic source resulting from near surface magnetic source (these are near surface intrusions) which are high frequency magnetic sources and the depth to the deep magnetic source $\left(D_{1}\right)$ from low frequency magnetic sources (deep basement within the sediments). Table 1 gives the values of $D_{1}$ and $D_{2}$ for the 40 blocks obtained from similar figures like figure 13 .

The shallow magnetic source depth ranges from 500 meters to 260 meters and an average of 370 meters as seen in figure $14 \mathrm{a}$ and $14 \mathrm{~b}$, the depth to the deep magnetic source ranges from 3500 meters to 6300 meters and an average of 4900 meters figure $15 \mathrm{a}$ and $15 \mathrm{~b}$, this is an indication that the area has good prospect for hydrocarbon formation as a $2 \mathrm{~km}$ is required for hydrocarbon formation, the 3D map of the deep basement depth $\left(D_{1}\right)$ show the wide variations in sedimentary thickness from place to place, the area with the thickest sedimentary cover is around Awgu, Enugu and the northern part of Ejekwe (Oju area) with values ranging from $5 \mathrm{~km}$ and above, the area with thin sedimentary thickness corresponds with the areas with much structural activities resulted from the Near surface short wavelength response intrusives (Igunmale and Abakaliki), the result shows a lot of consistency with the work of Kogbe (1989) who determined the average sedimentary thickness to be $3.03 \mathrm{~km}$. Similarly, Ofoegbu and Onuoha (1991) showed that the basement depth vary from $1.2 \mathrm{~km}$ to $2.5 \mathrm{~km}$ in some part of Anambra Basin and the study area of this research covered part of the Anambra Basin, Umego (2013), obtained basement depth for deeper magnetic sources to vary between $1.16 \mathrm{~km}$ and $6.13 \mathrm{~km}$ but with an average depth of 3.03 at area around Udi and Ezeagu region.

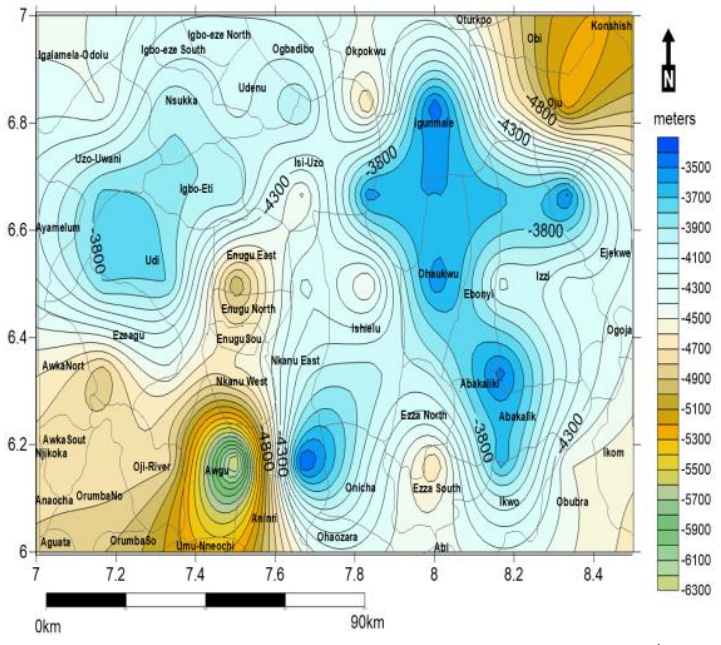

Fig 15a: 2D deep magnetic anomaly source depth $\left(D_{1}\right)$

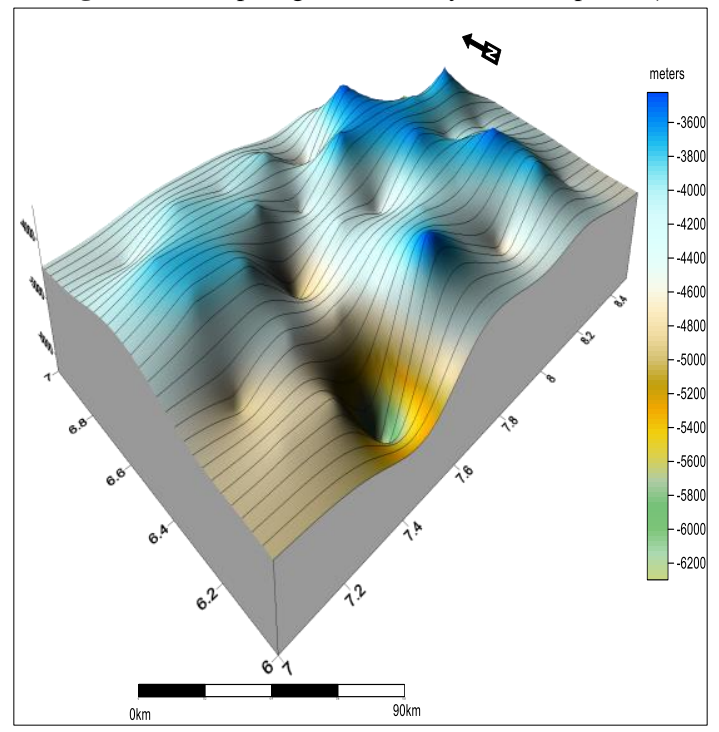

Fig 15b: 3D Deep Magnetic Depth Source Model $D_{1}$

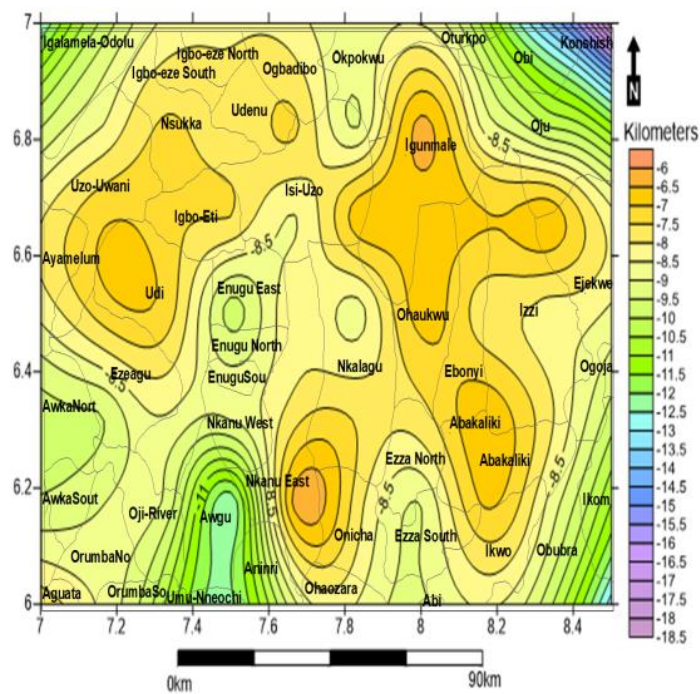

Fig 16: The Curie depth estimate map over the area of study 
The Curie depth was determined from the spectral depth value, the sedimentary thickness estimate of the study area from the spectral depth shows two type of lower layer boundaries of magnetized rocks, the curie depth point corresponds with the point depth with high temperature which causes the loss of magnetism in rocks. The Curie depth map shows that the curie isotherm based on the spectra analysis lies between depth of $12.3699 \mathrm{~km}$ to $6.34048 \mathrm{~km}$ and an average of $8.07594 \mathrm{~km}$ within the area. The curie depth map is displayed in figure 16 shows the depth variation at which rocks losses their magnetism due to temperature within the subsurface in the area of study, the results show that the rock units around Igunmale, Abakaliki, Nsukka, and Ejekwe will lose their magnetism at depth of around $6 \mathrm{~km}$, and areas around Awgu, Oju and Enugu will lose their magnetism around the depth of $10 \mathrm{~km}$, this result has some consistency with the earlier studies of Curie depths ranging mostly $10 \mathrm{~km}-23 \mathrm{~km}$ by Onwuemesi 1997; Nwankwo 2015; Chukwu et al. 2017 for areas with Deep basement, the lowest depth $(11 \pm 2 \mathrm{~km})$ is calculated around Abakaliki area that could be related to the Abakaliki anticlinorium according to Ofoegbu and Onuoha 1991.

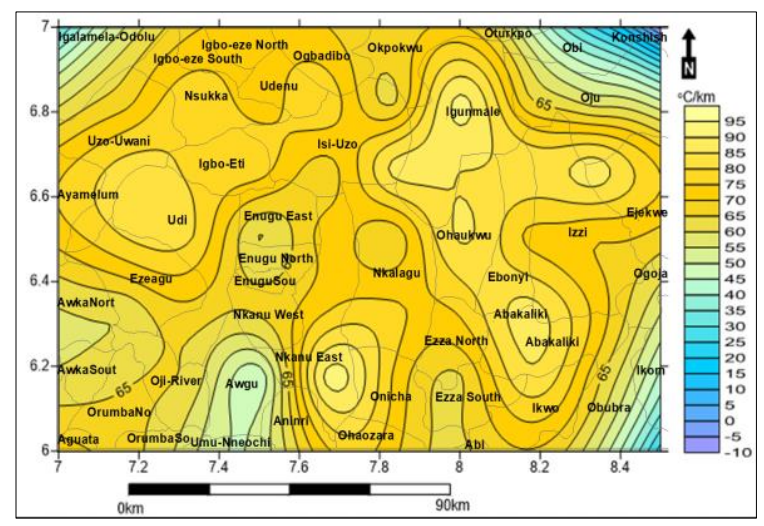

Fig 17: The geothermal Gradient map over the area.

The Geothermal gradient of the area ranges from 47 ${ }^{\circ} \mathrm{C} / \mathrm{km}$ to $91^{\circ} \mathrm{C} / \mathrm{km}$ with an average value of 73 ${ }^{\circ} \mathrm{C} / \mathrm{km}$, the geothermal gradient value range of the area shows negligible vast range between the minimum and the maximum value, and it can also be observed that the areas with higher Geothermal gradient are dominated by high frequency anomalies compared to others, this is due to the presence of high level near surface intrusive within these areas as shown in the residual anomaly map and the derivatives maps. Curie depth has an inverse relationship with geothermal gradient, areas with deeper curie depth points have low geothermal gradient, and the geothermal gradient map over the area is displayed in figure 17. Previous work by Onuoha and Ekine 1999 shows that the temperatures within the Anambra Basin (around
Nsukka and Enugu) increase with depth, geothermal gradients are expectedly to be moderately high at the edge of the Abakaliki anticlinorium and that the over pressured formations at depths are associated with higher geothermal gradients. The geothermal gradient value observed from the drilled well has a value of 49 ${ }^{\circ} \mathrm{C} / \mathrm{km}$, which is within the range of the result obtained from analysis in this research using the aeromagnetic data across the area. The heat flow gives us the idea of heat energy distribution in the subsurface, the Heat flow values used to produce map in figure 18 was obtained from the value of the Geothermal gradient and the mean average thermal conductivity of $2.5 \mathrm{Wm}^{-}$ ${ }^{1}{ }^{\circ} \mathrm{C}^{-1}$ as seen in table 1 , the study area is characterised by values between 110 and $212 \mathrm{~mW} / \mathrm{m}^{2}$ and an average of about $170 \mathrm{~mW} / \mathrm{m}^{2}$ for the heat flow rate over the area, the variation of this the rate of heat flow within the earth is as a result of the lithological variations observed from one region to another within the earth crust, it is observed from the map that the areas around Igunmale, Abakaliki, Udi, Ejekwe and some area around Nkanu East have high heat flow rate compared to others, these must have resulted due to the high presence of intrusive rock around those areas compared, the geothermal gradient and the heat flow map shows high spatial correlation (Meaning that the areas with high geothermal gradient also have high heat flow value), areas with High heat flow rate are seen to have a shallow curie depth point and viceversa, areas with much lithological intrusive and high structural activities are said to have high rate of heat flow, Onuoha and Ekine 1999 got a heat flow peak value of $76+/-3 \mathrm{~mW} / \mathrm{m}^{2}$ from some of the hydrocarbon well drilled within Anambra basin and they got higher values for other wells near Onitsha and Asaba, this validates the authenticity and the accuracy of our result gotten from a non-direct measurement of heat flow using the aeromagnetic map from our research work.

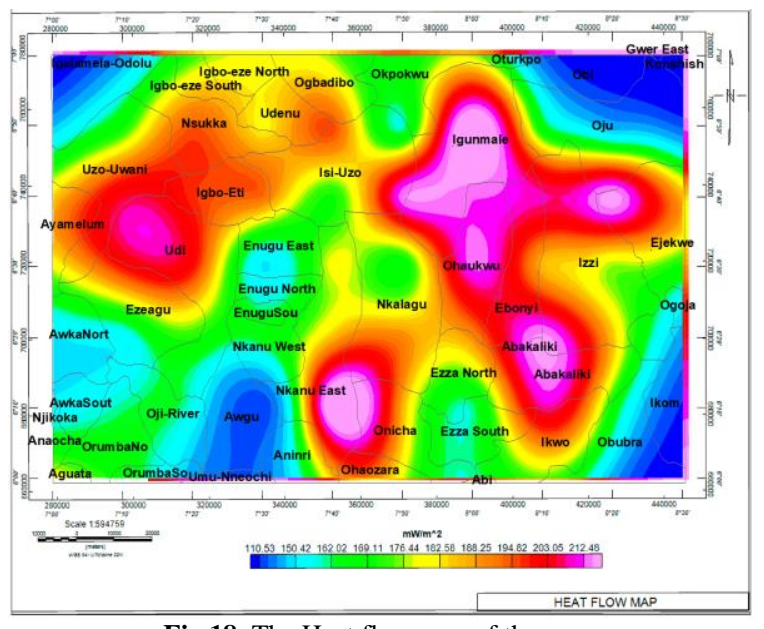

Fig 18: The Heat flow map of the area. 
Table 1: Summary of the results from the spectral depth, curie depth, geothermal gradient, and the heat flow values for each of the spectral blocks 1 to 40 over the area.

\begin{tabular}{|c|c|c|c|c|c|c|c|}
\hline $\begin{array}{l}\text { Spectral } \\
\text { block } \\
\text { no }\end{array}$ & $\begin{array}{l}\text { Mid-point } \\
\text { Northing } \\
\text { (deg.dec) }\end{array}$ & $\begin{array}{l}\text { Mid-point } \\
\text { Easting } \\
\text { (deg.dec) }\end{array}$ & $\begin{array}{l}\text { Deep } \\
\text { depth } \\
(\mathrm{m})\left(\mathrm{D}_{1}\right)\end{array}$ & $\begin{array}{l}\text { Shallow } \\
\text { depth }(\mathrm{m}) \\
\left(\mathrm{D}_{2}\right)\end{array}$ & $\begin{array}{l}\text { Curie } \\
\text { Point } \\
\text { Depth }(\mathrm{Km})\end{array}$ & $\begin{array}{l}\text { Geothermal } \\
\text { Gradient } \\
{ }^{\circ} \mathrm{C} / \mathbf{k m}\end{array}$ & $\begin{array}{l}\text { Heat } \\
\text { Flow } \\
\left(\mathrm{mW} / \mathrm{m}^{2}\right)\end{array}$ \\
\hline 1 & 6.166667 & 7.166667 & 4713.653 & 404.967 & 9.022339 & 64.28488 & 160.7122 \\
\hline 2 & 6.166667 & 7.333333 & 4758.469 & 339.005 & 9.177933 & 63.19506 & 157.9876 \\
\hline 3 & 6.166667 & 7.5 & 6407.821 & 445.736 & 12.36991 & 46.88799 & 117.22 \\
\hline 4 & 6.166667 & 7.666667 & 3350.268 & 333.248 & 6.367288 & 91.09059 & 227.7265 \\
\hline 5 & 6.166667 & 7.833333 & 4090.741 & 395.776 & 7.785706 & 74.49549 & 186.2387 \\
\hline 6 & 6.166667 & 8 & 4709.717 & 427.456 & 8.991978 & 64.50194 & 161.2548 \\
\hline 7 & 6.166667 & 8.166667 & 3635.886 & 334.797 & 6.936975 & 83.60993 & 209.0248 \\
\hline 8 & 6.166667 & 8.333333 & 4489.922 & 391.43 & 8.588414 & 67.53284 & 168.8321 \\
\hline 9 & 6.333333 & 7.166667 & 4889.609 & 335.565 & 9.443653 & 61.41691 & 153.5423 \\
\hline 10 & 6.333333 & 7.333333 & 4431.847 & 407.364 & 8.45633 & 68.58767 & 171.4692 \\
\hline 11 & 6.333333 & 7.5 & 4606.156 & 417.912 & 8.7944 & 65.95106 & 164.8776 \\
\hline 12 & 6.333333 & 7.666667 & 4058 & 325.607 & 8.11652 & 71.4592 & 186.1065 \\
\hline 13 & 6.333333 & 7.833333 & 3949.676 & 283.152 & 7.6162 & 76.15346 & 190.3837 \\
\hline 14 & 6.333333 & 8 & 3983.074 & 322.637 & 7.643511 & 75.88136 & 189.7034 \\
\hline 15 & 6.333333 & 8.166667 & 3453.604 & 255.432 & 6.651776 & 87.19476 & 217.9869 \\
\hline 16 & 6.333333 & 8.333333 & 4103.597 & 374.1 & 7.833094 & 74.04482 & 185.112 \\
\hline 17 & 6.5 & 7.166667 & 3802.197 & 387.313 & 7.217081 & 80.3649 & 200.9123 \\
\hline 18 & 6.5 & 7.333333 & 3799.524 & 365.344 & 7.233704 & 80.18022 & 200.4506 \\
\hline 19 & 6.5 & 7.5 & 5023.435 & 352.381 & 9.694489 & 59.82781 & 149.5695 \\
\hline 20 & 6.5 & 7.666667 & 4172.432 & 284.184 & 8.06068 & 71.95423 & 179.8856 \\
\hline 21 & 6.5 & 7.833333 & 4537.57 & 388.384 & 8.686756 & 66.76831 & 166.9208 \\
\hline 22 & 6.5 & 8 & 3536.305 & 307.111 & 6.765499 & 85.72908 & 214.3227 \\
\hline 23 & 6.5 & 8.166667 & 4143.794 & 464.465 & 7.823123 & 74.13919 & 185.348 \\
\hline 24 & 6.5 & 8.333333 & 4250.9 & 300.204 & 8.201596 & 70.71794 & 176.7949 \\
\hline 25 & 6.666667 & 7.166667 & 3771.465 & 466.478 & 7.076452 & 81.96198 & 204.9049 \\
\hline 26 & 6.666667 & 7.333333 & 3864.902 & 358.602 & 7.371202 & 78.68459 & 196.7115 \\
\hline 27 & 6.666667 & 7.5 & 3900.547 & 295.225 & 7.505869 & 77.27286 & 193.1822 \\
\hline 28 & 6.666667 & 7.666667 & 4514.593 & 501.932 & 8.527254 & 68.01721 & 170.043 \\
\hline 29 & 6.666667 & 7.833333 & 3540.069 & 358.735 & 6.721403 & 86.29151 & 215.7288 \\
\hline 30 & 6.666667 & 8 & 3601.904 & 387.537 & 6.816271 & 85.09051 & 212.7263 \\
\hline 31 & 6.666667 & 8.166667 & 3668.923 & 369.906 & 6.96794 & 83.23837 & 208.0959 \\
\hline 32 & 6.666667 & 8.333333 & 3486.982 & 351.744 & 6.62222 & 87.58392 & 218.9598 \\
\hline 33 & 6.833333 & 7.166667 & 4412.882 & 347.903 & 8.477861 & 68.41348 & 171.0337 \\
\hline 34 & 6.833333 & 7.333333 & 3907.403 & 396.933 & 7.417873 & 78.18953 & 195.4738 \\
\hline 35 & 6.833333 & 7.5 & 4151.475 & 329.561 & 7.973389 & 72.74197 & 181.8549 \\
\hline 36 & 6.833333 & 7.666667 & 3873.029 & 357.502 & 7.388556 & 78.49978 & 196.2494 \\
\hline 37 & 6.833333 & 7.833333 & 4724.34 & 408.906 & 9.039774 & 64.1609 & 160.4022 \\
\hline 38 & 6.833333 & 8 & 3407.37 & 474.264 & 6.340476 & 91.47578 & 228.6895 \\
\hline 39 & 6.833333 & 8.166667 & 4527.067 & 360.324 & 8.69381 & 66.71413 & 166.7853 \\
\hline 40 & 6.833333 & 8.333333 & 5278.665 & 497.572 & 10.05976 & 57.65546 & 144.1387 \\
\hline
\end{tabular}

Conclusion: The structural extent and trend of the rocks is in the ENE-WSW and NE-SW direction, the structures prominent around Ejekwe, Ebonyi, Igunmale, Nsukka, and Enugu, resulted from latter intrusive which are often associated with mineral deposits. The curie depth, geothermal gradient and the Heat flow over the area calculated revealed that the average curie depth for the area is $8 \mathrm{~km}$, the average geothermal gradient is $73^{\circ} \mathrm{C} / \mathrm{km}$, and the average heat flow rate over the area is $170 \mathrm{~mW} / \mathrm{m}^{2}$. This research revealed that energy or power generation problem in south-south and southeast Nigeria could be solved if a geothermal plant is installed within the study area which had above the minimum heat flow requirement for geothermal energy generation $\left(>80 \mathrm{~mW} / \mathrm{m}^{2}\right)$ as proposed by Blackwell et al., 2000 in his research for U.S. Department of Energy, Assistant Secretary for
Energy Efficiency and Renewable Energy Washington, DC.

\section{REFERENCES}

Abraham, EM; Obande, EG; Chukwu, M; Chukwu, CG; Onwe, MR (2015). Estimating depth to the bottom of magnetic sources at Wikki Warm Spring region, northeastern Nigeria, using fractal distribution of sources approach. Turkish J Earth Sci. 24 (5): 494-512.

Bhattacharyya, B K; Leu, LK (1975). Spectral analysis of gravity and magnetic anomalies due twodimensional structures, Geophysics. 40: 9931031.

Biswas, A (2017). A review on modeling, inversion and interpretation of self-potential in mineral 
exploration and tracing paleo-shear zones; Ore Geol. Rev. 91: 21-56.

Blackwell, DD; Wisian, KW; Richards, MC; Steele, JL (2000). Geothermal Resource Reservoir Investigations Based on Heat Flow and Thermal Gradient Data for the United States Department of Energy, Assistant Secretary for Energy Efficiency and Renewable Energy Washington, DC. Southern Methodist University Dallas, TX. 1-53.

El Sayed, IS (2016).The integration of gravity, magnetic and seismic data in delineating the sedimentary basins of northern Sinai and deducing their structural controls. J. Asian Earth Sci. 115: 345-367.

Fatoye, FB; Gideon, YB (2013). Geology and Mineral Resources of the Lower Benue Trough. Nigeria. Pelagia. Res. Lib. Adv. Appl. Sci. Res. 4 (6): 2128.

Kasidi, S; Nur, A (2012b). Curie depth isotherm deduced from spectral analysis of magnetic data over sarti and environs north-eastern Nigeria. Inter. J. Earth Sci. Eng. 5(5):1284-1290.

Nuri, DM; Timur UZ; Mumtaz, H; Naci, O (2005). Curie Point Depth variations to infer thermal structure of the crust at the African-Eurasian convergence zone, SW Turkey. J. Earth planets Space Vol. 57: 373- 383.

Offodile, ME (1976). The Geology of the Middle Benue, Nigeria. Publications from the Paleontological Institute, University of Uppsala, special vol, 4: 1-166
Ofoegbu, CO; Onuoha, KM (1991). Analysis of magnetic data over the Abakaliki anticlinorium of The Lower Benue Trough, Nigeria. Marine and Petroleum Geology. 8:174-183.

Okubo, YJR; Graf, RO; Hansen, K; Ogawa, TH (1985). Curie point depth of the Island of Kyushu and surrounding areas, Japan Geophysics. 53:481-491.

Olade, MA (1975). Evolution of Nigeria's Benue Trough (aulacogen): a tectonic model. Geological Magazine. 112: 575-583.

Onuoha, KM; Ekine, AS (1999). Subsurface temperature variations and heat flow in the Anambra Basin, Nig. J. Afr. Earth Sci. 28, 3: 641652.

Spector, A; Grant, F (1970). Statistical models for interpreting aeromagnetic data. Geophysics, 35: 293-302.

Tselentis, GA (1991). An attempt to define Curie depth in Greece from Aeromagnetic and heat flow data. PAGEOPH, Vol. 136, No.1, 87-101.

Wolfson, R (2012). "Energy from Earth and Moon" in Energy, Environment, and Climate, 2nd ed., New York, NY: W.W. Norton \& Company, ch. 8: 204224.

Witter, J.B., Siler, D.L., Faulds, J.E. and Hinz, N. H. (2016). 3D geophysical inversion modeling of gravity data to test the 3D geologic model of the Bradys geothermal area, Nevada, USA. Geothermal Energy 4: 14. 